\title{
Disentangling the greenhouse
}

Continuing uncertainties about the working of the greenhouse enhancement give the lie to those demanding, at a meeting last week in the Netherlands, that the details of an international convention should be settled on the spot.

\section{Melbourne}

EVERYBODY seems to know that this is the part of the Earth's surface at which the Antarctic ozone hole reaches furthest north. While the observations of anomalous springtime ozone depletion outside the Antarctic Circle covers only a single season (this time last year), people seem convinced that this will be the beach summer of total block, of warmth without $\tan$ (see Nature 340, 290-294; 1989). Australians do not lightly forgo such pleasures, which is why some wonder how long-lasting will be the resolve to keep ultraviolet away from skin.

But even in literate Australia, the confusion between the ozone hole and what is strictly the supposed enhancement of the normal greenhouse effect by atmospheric constituents opaque to infrared is as profound as elsewhere. There may be rough justice in that. The springtime Antarctic ozone hole, the reality of which seems well-attested by this season's observations, is at least a sign that a measurable property of the atmosphere is affected by the rate at which unwanted refrigerants are discharged to the atmosphere. If chlorofluorocarbons (CFCs) can affect the ozone layer, why should not the much more copious releases of other greenhouse gases, such as carbon dioxide, affect the climate?

The confusion is nevertheless a threat to good causes, some of which are also green. CFCs are greenhouse gases in their own right (and, molecule for molecule, are more effective than $\mathrm{CO}$. But to a first approximation, ozone depletion, whatever its cause, does not affect the climate or even the weather. To a second approximation, of course, ozone depletion (and so CFCs) affect both climate and weather through the changed variation of temperature with altitude - the tropopause is lowered - but the consequences cannot easily be predicted quantitatively let alone disentangled from the data.

How can the distinction between the ozone hole and the enhancement of the greenhouse effect best be established as a part of general knowledge? Much might be done by the direct measurement of the spectrum of solar ultraviolet radiation reaching the surface of the Earth at different places and seasons. The most obvious practical impediments are those of calibration, which, in the absence of data from the past, must necessarily be abso- lute. Even so, it is remarkable that so little has so far been said about the flux of ultraviolet light reaching the surface of the Earth in even recent years. Paradoxically, if it were shown that ozone depletion means extra ultraviolet, it would be easier to separate that from the direct enhancement of the greenhouse.

While there should by now be no doubt that the next practical step should be the negotiation of an international convention to restrict the release of all greenhouse gases, the more obdurate impediments to understanding and prediction remain as obdurate as ever. It is maddening that the big uncertainties seem to change only slowly with the passage of time. Two stand out. The climate models can incorporate what is called average cloudiness, but the effect of real clouds, with real edges, on the heat balance in the troposphere could be qualitatively different. In principle if not in magnitude, the uncertainties are like those of estimating the role of clouds in nuclear winter (see Nature 318; 99; 1985). That must remain a problem.

The other big uncertainty, at least so far as the greenhouse enhancement due to $\mathrm{CO}_{2}$ is concerned, remains that of knowing the fate of whatever fraction of the atmospheric content is dissolved in the oceans every year. Increased conversion to inorganic carbon would be benign, solution as bicarbonate in a steadily deepening layer of warm water above the oceanic thermocline would be the opposite. That issue has been endlessly discussed, but there are few who at this stage would put their hands on their hearts and say they know the quantitative truth.

Even relatively operational questions, that of the movement of $\mathrm{CO}_{2}$ within the oceans for example, are unresolved. That is nicely illustrated by an attempt last year, by Peter G. Brewer and Catherine Goyet of the Woods Hole Oceanographic Institution and David Dyrssen of the Chalmers Institute of Technology at Gothenburg, to measure the northwards flux of $\mathrm{CO}$, in the North Atlantic (Science 246, 477; 1989). The North Atlantic is usually supposed to be a substantial sink for the gas, which is supposed to be carried northwards by oceanic currents. But measurements across the Florida Gulf and at three stations along the 25th parallel in midAtlantic lead to the conclusion that while there is a substantial northerly transport, that is almost but not quite offset by trans- port in the opposite direction. The net northwards flux, at 260 million tonnes a year, is just over one per cent of the flux in either direction, or just under 5 per cent of the annual production of this greenhouse gas. This is much smaller than expected.

What can be the explanation? One is that the data may be insufficient. Three sets of measurements of $\mathrm{CO}_{2}$ concentration with depth are not many, although the authors of the study have used previous survey data to interpolate between their stations. Another is that, while $\mathrm{CO}_{2}$ will be released as the lower waters of the Gulf Stream reach the surface, it will be reabsorbed from the atmosphere as the Gulf Stream cools, reducing the partial pressure of the gas. Still another is that expectations are not yet fulfilled because there has not been enough time, since the onset of rapid greenhouse gas production half a century ago, for the deep waters of the North Atlantic to have travelled as far north.

In the circumstances, it must plainly be foolhardly to pretend just what the future course of the enhancement of the greenhouse effect will amount to. Better and more measurements will help, although none will be decisive. But if more were known of the variation of $\mathrm{CO}_{2}$ concentration with latitude in the deep waters of the Atlantic, it might at least be possible to guess when transport into the North Atlantic atmosphere would become substantial. That would provide a means of telling just how quickly the international convention must be negotiated and brought into effect.

Questions such as these were plainly in the minds of some of those attending last week's meeting in the Netherlands, one of several meetings planned as preparation for the more formal diplomatic conferences to be held next year. Governments such as the British were pilloried, but unfairly, for having asked that the details of a convention - the date at which the further accumulation of greenhouse gases should be halted, for example - should await further study. That, of course, is entirely sensible. It is in nobody's interests that the economic disruption an international convention will certainly bring should be accelerated. It is not that there is nothing else to talk about, the demand on behalf of developing countries for fair shares in any quota system there may be for one thing.
John Maddox 